\title{
Informe NOLAN (Normas de conducta de la vida pública)
}

Manuel Martínez Bargueño*

\section{Introducción}

La Comisión Nolan, que toma el nombre de su Presidente Lord Nolan, juez de profesión, fue creada en octubre de 1994, a instancias del Primer Ministro John Major, a fin de investigar ala creciente inquietud que se estaba produciendo en la sociedad respecto de determinados comportamientos en la Función Pública.

En efecto, durante los años 90, se sucedieron en Gran Bretaña un aluvión de acusaciones sobre el comportamiento de los hombres públicos (parlamentarios, políticos, altos funcionarios) que, consideradas en su conjunto, than creado un clima generalizado de degeneración ética, en el que los escándalos de tipo económico, político y sexual aparecen mezclados.

Entre los casos de corrupción económica se cuentan, por ejemplo, los sobornos a diputados para obtener tratos de fa-

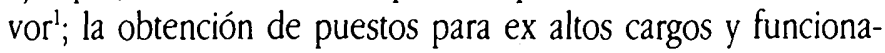
rios en empresas en cuya privatización han participado o con las que han tenido relación durante su mandato; las acusaciones de relación entre obediencia política y nombramientos, fraude y malversación en "quangos" (organizaciones no gubernamentales, cuasi autónomas que realizan algunas funciones públicas de administración o asesoramiento) como los habidos en la Sociedad para el Desarrollo del País de Gales y acusaciones de que los ministros han aceptado favores que crean conflictos de intereses con sus funciones públicas.

Además de los casos de corrupción económica, ha habido denuncia por casos reales o supuestos de abuso de poder politico, como el famoso caso de venta de armas a Irak (denunciado por Sir Richard Scott), corrupción y prevaricación en los ayuntamientos, nombramiento de altos cargos en "quangos" por afinidad política y reticencia de los ministros a dimitir por este tipo de asuntos. Sí han sido, en cambio, seguidas de dimisiones, las acusaciones de escándalo sexual, demasiado numerosas para ser recordadas.

Todo ello ha creado en Gran Bretaña un clima general de enrarecimiento, en el cual la veracidad de determinados grupos profesionales (jueces, periodistas, clero, políticos, miembros del Gobierno) ha sido puesta en tela de juicio por la opinión pública, tal como reflejan las encuestas (Cuadro 1).

\begin{tabular}{|l|c|c|c|}
\hline \multicolumn{4}{|c|}{ Cuadro 1 } \\
Porcentaje de veces que dicen la verdad \\
\hline & 1983 & 1993 & Variación \\
\hline Clero & 85 & 80 & -5 \\
\hline Médicos & 82 & 84 & +2 \\
\hline Catedráticos & 79 & 84 & +5 \\
\hline Jueces & 77 & 68 & -9 \\
\hline Profesores & - & 70 & - \\
\hline Locutores de televisión & 63 & 72 & +9 \\
\hline Policía & 61 & 63 & +2 \\
\hline Ciudadano de a pie & 57 & 64 & +7 \\
\hline Entrevistadores & - & 52 & - \\
\hline Funcionarios & 25 & 37 & +12 \\
\hline Grandes empresarios & 25 & 32 & +7 \\
\hline Periodistas & 19 & 10 & -9 \\
\hline Sindicalistas & 18 & 32 & +14 \\
\hline Políticos & 18 & 14 & -4 \\
\hline Ministros del Gobierno & 16 & 11 & -5 \\
\hline
\end{tabular}


La empresa de estudios de opinión Market and Opinion Research International (MORI), realizó en 1983 y 1993 en Inglaterra, dos sondeos. Para ello distribuyó entre los encuestados una lista de grupos profesionales de los que se pretendía saber su credibilidad. Los resultados mostraron que ministros y políticos se disputaban con los periodistas los últimos puestos en esta categoría. Como aparece en el Cuadro 1, la mayoría de los grupos ha mejorado su imagen entre 1983 y 1993; mientras que la de ministros y políticos, ya baja entonces, ha empeorado.

El Comité pidió al historiador del partido conservador Lord Blake que explicara las causas de la caída de los políticos en la estima pública. Este explicó y así lo recoge el Informe (pág. 104) que los escándalos financieros no son de ahora, añadiendo a continuación ppero algo ba sucedido más recientemente y pienso que puede estar relacionado en parte con un tipo de mentalidad de enriquecimiento rápido que imperó durante la era eduardiana y que ba sido bastante prevalente en los últimos veinte años y ello tiene una especie de efectos propagadores. El epitafio de Lord Blake es el baldón de una época que se acaba².

La preocupación de la opinión pública es lo que indujo al Primer Ministro a crear esta comisión, en la fecha citada, presidida por Lord Nolan, juez de profesión, que ha trabajado con un equipo de nueve personas, en el que hay un representante de cada uno de los tres principales partidos.

\section{Líneas de actuación / objetivos}

La Comisión Nolan empleó seis meses en realizar la investigación encargada por el Primer Ministro. Para ello recabó cerca de cien testimonios y recibió unas 2.000 cartas de todo tipo de personas y sobre toda clase de asuntos.

La investigación se concentró en Miembros del Parlamento (MP), Ministros, Funcionarios, Cuadros Directivos de los Quangos y Cuerpos del Servicio Nacional de Sanidad.

A lo largo de la investigación, quedó claro que el actual recelo de los ciudadanos se basa más que en pruebas fehacientes de deshonestidad en suposiciones y conjeturas. En relación en concreto, con los funcionarios, la Comisión asevera que aaunque siempre babrá una minoria que incumpla", por regla general, creemos que la gran mayoria de los empleados públicos británicos son bonestos y muy trabajadores y observan altos valores éticos.

Ante el aumento de preocupación social por el deterioro en el cumplimiento de las normas de conducta, la Comisión juzga que "no podemos afirmar de un modo concluyente que las normas de conducta en la vida pública se estén incumpliendo", sin embargo, reconoce que axisten fallos en los procedimientos para mantener y bacer cumplir tal normativa. El resultado es "que los miembros de la Función Pública no tienen siempre claro cuál es el limite para una conducta aceptable en su actuación.

Por eso, uno de los dos objetivos del Informe es aaportar claridad y orientación allá donde se presente la incertidumbre moral; el otro es restablecer la "confianza del ciudadano" en el actuar de la Administración.

\section{Recomendaciones generales}

Estas tienen aplicación general para toda la Función Pública y son las siguientes:

- Principios de la Función Pública: los siguientes siete principios deben presidir la actuación de toda la Función Pública y aplicarse en todos los ámbitos, en cuanto que todos sirven de algún modo al interés público:

- Altruismo: los que detentan puestos públicos deben tomar decisiones únicamente por el interés público. No deben hacerlo para obtener recompensa material o económica para ellos, su familia o terceras personas.

- Integridad: no deben ejercer actividades exteriores que puedan influir en su actuación como funcionario.

- Objetividad: en la realización de cualquier actividad pública, incluyendo nombramientos públicos, adjudicación de contratos, y transferencias de fondos, su decisión deberá estar basada en criterios objetivos.

- Responsabilidad: en sus acciones y decisiones públicas se deben someter a cualquier investigación que se realice en su departamento.

- Transparencia: en todas sus acciones y decisiones, en la medida de lo posible. Deberán justificar sus decisiones o restringir la información sólo cuando el interés público claramente lo requiera.

- Honestidad: deben declarar cualquier actividad privada que pueda interferir en su cargo público y resolver cualquier conflicto de forma que se proteja el interés general.

- Liderazgo: Deben promover y apoyar estos principios mediante el ejercicio del liderazgo y la ejemplaridad.

- Códigos de conducta. Los principios anteriores deben constituir la base de los códigos de conducta de todo el sector público redactados dentro de cada organismo para que se adapte mejor a sus circunstancias y pueda formar parte de la cultura de cada organización. Recientemente los Ministros han aprobado un nuevo código para los 
funcionarios y también, la mayor parte de los Quangos tienen ya sus códigos. El Informe recomienda que haya códigos para Ministros y Parlamentarios.

- Auditorias independientes. En aquellos lugares donde exista riesgo de que se produzcan fallos en el cumplimiento de las normas de comportamiento, los sistemas de control interno deben ser asistidos por auditorías independientes, como garantía adicional para mantener la confianza del ciudadano.

- Orientación y educación. A causa del ritmo de los cambios habido en el sector público (descentralización, contratación externa de los servicios públicos, intercambio con otros sectores, resistencia de los escépticos, etc.), no todos los funcionarios están en condiciones de asimilar la nueva cultura del servicio público a menos que se les aclare lo que se espera de ellos y esto se refuerce de manera sistemática.

Para inculcar altos valores éticos, hay la necesidad de una mayor promoción en la consolidación de las normas de conducta a través de la orientación, la educación y la formación sobre todo en la fase de ingreso en la vida pública. La orientación profesional supone la participación activa de todos los Cuerpos de la Administración en la definición de los valores éticos más importantes, en la predicación con el ejemplo de los funcionarios más experimentados y en la comprobación de que estos principios se asumen, tomando, en caso necesario, las medidas para que esto se cumpla.

\section{El Gobierno: Ministros y Funcionarios}

Del extenso Informe Nolan (108 páginas), manejamos exclusivamente el capítulo 3 (páginas 46 a 64), relativo al Gobierno: Ministros y Funcionarios, prescindiendo de la parte dedicada a Miembros del Parlamento, Cuadros Directivos de los Quangos y Cuerpos del Servicio Nacional de Sanidad.

Ministros y Funcionarios son, junto con los MP, quienes juegan el papel más importante en la elaboración y realización de las políticas, por lo que el cumplimiento de las normas de conducta en ambos se debe elevar al máximo.

Durante la realización del Informe, la Comisión detectó situaciones que provocan la desconfianza del público. Por ejemplo, la facilidad con que los ex Ministros pueden obtener empleo en las empresas con las que han tenido relación cuando estaban en el Gobierno, o el peligro de incumplimiento de las normas éticas de conducta por los funcionarios públicos en casos de contratación externa de los servicios públicos.

\section{La conducta de los Ministros}

El público tiene derecho a esperar un comportamiento intachable de los Ministros, tanto en el plano personal como en el económico, pero con una diferencia fundamental: así como las conductas privadas, sólo en ocasiones pueden condicionar el ejercicio de su cargo (por ejemplo, cuando su conducta resulta contradictoria con algún tipo de política, da lugar a un espectáculo bochornoso o puede suponer un riesgo para la seguridad del Estado), los delitos económicos afectan a todos porque atacan la esencia de la confianza que la gente deposita en la actuación de los gobernantes.

La regulación de la actuación de los Ministros se recoge en las Normas de Procedimiento para Ministros (NPM), documento que data de 1945, aunque toma elementos anteriores y que fue publicado en 1992. Las NPM, aunque sin rango constitucional, son de obligatorio cumplimiento para todos los miembros del Gobierno.

Las NPM se han definido como una mezcla de principios inmutables con recetas domésticas. (Peter HeNNESSEY). Comienzan con el establecimiento de algunos principios fundamentales:

Será cada Ministro en particular quien establezca la forma de actuar para que se cumplan las normas de conducta de la mejor manera posible. Los Ministros deberán evitar que se produzca algún conflicto entre su esfera particular y la pública. Buscarán la mayor transparencia posible con el Parlamento y con el público. Estas notas se considerarán bases de las obligaciones generales.

La Comisión entiende que este documento debiera ser redactado de nuevo apara formar un código de conducta con rango de Ley, de manera que los principios generales se vean acompañados por normas de detalle, cuando fuera necesario. Por ejemplo:

- Los Ministros deben asegurarse de que no surjan conflictos entre su cargo oficial y sus actividades privadas.

- Los Ministros no deben engañar al Parlamento. Deben mostrarse lo más accesible que puedan con el Parlamento y con el público.

- Los Ministros son responsables ante el Parlamento de las politicas y de la actuación de los organismos de ellos dependientes.

- Los Ministros deben evitar aceptar cualquier regalo o trato de favor que pueda comprometer su imparcialidad 0 les induzca a actuar indebidamente.

- Los Ministros de la Cámara de los Comunes deben separar su actividad de Gobierno con la de Diputados electos de la misma.

- Los Ministros deben mantener su actividad de gobierno separada de la de su partido. No deben obligar a los fun- 
cionarios a su cargo a que realicen actividades de partido ni a otras que puedan entrar en conflicto con el Código de la Función Pública.

La Comisión considera que si el Gobierno ha aceptado la propuesta de elaborar un Código de Conducta para los funcionarios, el mismo esquema debe aplicarse a los Ministros.

\section{Las actividades de los Ex-Ministros}

Uno de los aspectos de la conducta de los Ministros que más preocupan en Gran Bretaña es la ausencia de normas que regulen su actividad profesional al abandonar el Gobierno. Mientras que para los funcionarios y para los militares hay normas en vigor, desde hace mucho tiempo, que tratan de asegurar que su actuación durante su empleo oficial no quede condicionada por la perspectiva de obtener algún trato de favor cuando dejen su cargo oficial, los Ministros actualmente pueden incorporarse a la actividad que deseen, lo que según el Informe de la Comisión "resulta dificil de justificar.

La Comisión recomienda en este punto que se aplique a los Ministros un sistema similar al de funcionarios, el cual consiste básicamente en lo siguiente:

Todos los funcionarios con los grados 1 y $1 \mathrm{~A}$ (secretario permanente) y 2 (secretario suplente) deben someter sus planes de empleo futuro a examen de la Comisión Asesora de las Actividades de los Ex-Funcionarios, compuesta por políticos retirados, funcionarios, diplomáticos y militares, a menos que se trate de un trabajo no remunerado en una organización sin animo de lucro o en otro organismo público.

Esta aprobación se extiende no sólo al trabajo inmediato sino a los sucesivos dentro del plazo de los dos años siguientes al abandono de su puesto en la Administración. La aprobación compete el Primer Ministro, previo dictamen de la Comisión Asesora.

Para todos los funcionarios de grados 1 y $1 \mathrm{~A}$ hay un período de espera de tres meses que puede ser alargado por recomendación de la Comisión Asesora, la cual puede también recomendar que se establezcan determinadas condiciones de comportamiento en los empleos futuros, por ejemplo, que se abstengan de tener relaciones con sus antiguos departamentos o de trabajar en proyectos para la Administración, condiciones que se pueden exigir incluso pasados los dos años después de dejar las tareas de gobierno.

Las normas anteriores se aplican también a funcionarios de nivel 2, aunque estos casos no son tratados por el Comité Asesor sino juzgados por el ministro competente. Para el nivel 3 y para los casos de nivel inferior que sean especialmente dedicados, se debe solicitar el dictamen previo de la Secretaría de la Presidencia.

Esta normativa, suficientemente contrastada y probada, bien aceptada por los funcionarios y por la opinión pública, es la que que la Comisión propone que se aplique también a los ExMinistros, con las siguientes puntualizaciones:

- Aplicación también a los Ex-Ministros del Gobierno de un periodo de espera de tres meses como a los secretarios permanentes de nivel 1 y $1 \mathrm{~A}$. Este plazo no sería aplicable a otros Ministros o Miembros del Parlamento. En los casos en que se recomiende un mayor período de espera, el máximo de ésta no debiera ser superior a dos años a partir del cese.

- Pueden existir circunstancias excepcionales que al despertar de antemano sospechas de irregularidad hagan que el interesado se abstenga de plantear una solicitud. En estos casos la Comisión Asesora debe ser capaz de persuadir al Ministro que cesa que su actitud no es procedente. Si, pese a todo, el Ministro se incorporara a esta actividad sospechosa, la Comisión hará público que su consejo no ha sido solicitado, acción que con la subsiguiente reacción de la opinión pública, pararia de inmediato tan desafortunado intento.

- Una vez conocido el informe de la Comisión Asesora, los Ex-Ministros tienen derecho de recurso al Primer Ministro quien podrá reducir el tiempo de periodo de espera o rebajar cualquier otra condición si el recurso estuviera bien fundado 3 .

- Cada año la Comisión Asesora deberá publicar un Informe que recoja los informes emitidos y casos acaecidos.

\section{Obsequios y regalos}

Este apartado del Informe hace referencia a la posible aceptación por parte de los Ex-Ministros de tratos privilegiados o viajes con gastos pagados (el agratis totaln, que decimos por estos pagos). El principio establecido en el párrafo 126 de las NPM de que ningún Ministro o funcionario acepte obsequios, trato de favor o atención de nadie que pueda ponerle en un compromiso le parece bastante claro a la Comisión que, sin embargo, recomienda una medida complementaria significativa al respecto: aque los Departamentos Ministeriales, además de registrar los obsequios recibidos también lo bagan de los casos de trato de favor aceptados por los Ministros en el ejercicio de su cargo. Este registro debe darse a conocer si asi se solicita.

\section{La Función Pública}

Dice el Informe que el ejercicio de la Función Pública está profusamente regulado en códigos de comportamiento, con 
reglas detalladas y principios generalmente aceptados que han estado en vigor desde la mitad del siglo pasado. Con la creación de las Agencias Ejecutivas en los años 80, el asunto de la vigencia de las normas de comportamiento pasó a un segundo plano y la prioridad se centró en la consecución de una mayor eficacia y eficiencia en la prestación del servicio público.

En términos generales -dice el Informe de la Comisión- ‘creemos que el comportamiento de los funcionarios sigue siendo muy satisfactorio y que los casos de corrupción flagrante y fraudes son raros aunque pueden llegar a ser graves en casos concretos.

En el Libro Blanco Avanzando en la Continuidad y en el Cambio, (1994), el Gobierno expresó de nuevo y confirmó los valores fundamentales que presiden la actuación de la Función Pública: integridad, imparcialidad politica, objetividad, selección y promoción por mérito y responsabilidad ante el Gobierno y el Parlamento. En este documento, el Gobierno opina que "con una mayor delegación y mayor movilidad de entrada y salida de personas en la Administración, se incrementa la necesidad de una mayor vigilancia en el cumplimiento de las normas de conducta.

Los cuatro objetivos a los que el Gobierno pretende llegar en materia de Función Pública son:

- El establecimiento de un nuevo Cuerpo superior de funcionarios.

- Un nuevo Manual de Procedimiento para los responsables de las Agencias Estatales.

- Un nuevo Código del funcionario.

- Una vía de recurso independiente para funcionarios ante Comisarios de Función Pública.

En relación con la creación de este nuevo Cuerpo superior de funcionarios, la Comisión recomienda que los complementos de productividad para este nuevo Cuerpo se definan de forma que no comprometan la imparcialidad política.

La Comisión considera también favorablemente la posibilidad de un nuevo Código "breve y claro" para funcionarios en el que se establezca el marco constitucional en el que se desarrolle su función, en plena concordancia con los principios de la Función Pública antes señalados.

En cuanto al sistema de recursos ante los Comisarios de la Función Pública, la Comisión sugiere que se introduzcan algunos cambios en el actual borrador de forma que cualquier funcionario que advierta la posible comisión de una actuación incorrecta o inadecuada pueda elevar recurso aun cuando no esté personalmente implicado e igualmente recomienda que la tramitación del recurso tenga la mayor difusión posible y que los Comisarios informen al Parlamento de todos los que prosperen.

No obstante, parece que la Comisión no confía mucho en la efectividad de este tipo de recurso -de hecho, hasta ahora exis- tía un procedimiento de recurso ante el Director General de la Función Pública, del que se ha hecho un escasísimo uso (sólo un recurso en ocho años)-. Por ello, la Comisión considera necesario que haya una vía paralela e informal que permita a los funcionarios plantear sus reclamaciones de forma confidencial y para ello sugiere que en los Departamentos Ministeriales y Agencias Estatales se nombren uno o varios encargados de la tramitación de las reclamaciones con carácter confidencial, nombramientos que deberían recaer en personas no pertenecientes a la organización pero que deberían recibir todo el apoyo de la Dirección cuando se alegue para investigación algún tipo de abuso. Alguna institución sin ánimo de lucro, como la de •Obras de Interés Social, parece que dispone ya de alguna de estas vías de carácter confidencial para la solución interna de los recursos, aunque no dejan de aparecer cautelas en torno a este punto.

\section{Códigos de conducta}

Esta cuestión preocupa mucho, lógicamente, a los redactores del Informe. Actualmente los Departamentos Ministeriales y las Agencias Estatales están capacitados para introducir normas de conducta en la medida que reflejen los principios y reglas establecidas en el denominado “Código de la Gestión de la Función Pública" (CGCP). En este Código se recogen, entre otras cosas, que los funcionarios deben ser (y parecer) honestos e imparciales y que, en concreto, no deben hacer uso indebido de la información oficial, no deben hacer nada que comprometa su imparcialidad política y no deben aprovechar su empleo oficial para su propio interés. El incumplimiento de estas normas puede dar lugar a una acción disciplinaria.

Según investigaciones propias de la Comisión, parece que muy pocos Departamentos o Agencias han hecho esfuerzos para llamar la atención sobre el cumplimiento de estas normas de conducta, salvo la repetición anual de una nota circular al respecto, lo que contrasta con una mayor exigencia de asunción de responsabilidades por funcionarios jóvenes de niveles inferiores, al haberse reducido el número de niveles superiores. Por esta causa, la Comisión recomienda que se realicen sondeos periódicos en Departamentos y Agencias sobre el conocimiento y comprensión de aquellas normas éticas que le son de aplicación y que, con respecto a aquellas partes de la normativa donde pueden aparecer conflictos, se debe efectuar una labor de orientación y aclaración con formación adicional.

\section{Actividades en el sector privado}

Actualmente los funcionarios que cesan en el sector público para pasar a trabajar en el sector privado deben presentar solicitud, ante la Comisión Asesora, (funcionarios de niveles 1 y 2), 
la Secretaría del Gobierno (funcionarios de nivel 3 o superiores) o los Departamentos. De las más o menos 1.000 solicitudes que se presentan al año, entre un $20 \%$ o un $30 \%$ son objeto de alguna sugerencia sobre períodos de espera u otras condiciones.

Este sistema funciona generalmente bien y consigue un equilibrio razonable entre el mantenimiento de la confianza en la opinión pública y la autorización a los funcionarios civiles a tener libertad de movimientos dentro de aquellas empresas del sector privado que no levanten sospechas de conflicto de intereses.

$\mathrm{Al}$ igual que para el caso de los Ministros, la Comisión recomienda a los funcionarios que se abstengan de hacer solicitudes improcedentes y que, en casos concretos, puedan hacerse públicas las decisiones, una vez incorporados los funcionarios a la nueva actividad.

\section{Aceptación de obsequios y tratos de favor}

En la actualidad las normas relativas a la aceptación de obsequios son bastante estrictas, incluso más ajustadas que las que se aplican a los Ministros. En la mayoría de los Departamentos, los funcionarios no están autorizados a aceptar más que regalos simbólicos hasta un valor de 125 libras (unas 24.000 pesetas) $)^{4}$.

La Comisión recomienda que se mantenga un registro central o departamental con las invitaciones para comidas y cenas de trabajo y otros actos de representación similares y que se dan instrucciones en que se especifiquen las circunstancias en las que se deberá solicitar opinión de la superioridad sobre la conveniencia de aceptar invitación o tratos de favor.

\section{Consecuencias del Informe}

La confusión, más que la corrupción es la causa principal de la erosión de las normas de conducta en la vida pública británica. Esta es quizás la primera gran conclusión del Informe Nolan, que, en general, ha sido bien acogido por la Prensa británica el Comité era necesario y su informe bienvenido" (The Guardian 12.5.95), "estos cambios propuestos son bienvenidos" (Financial Times), y, como era de esperar, con menor entusiasmo por Miembros del Parlamento, que de llevarse a efecto las recomendaciones del Informe Nolan, se verían obligados a dar explicaciones sobre sus actividades remuneradas de consultores o administradores de sociedades.

En el debate sobre el Informe Nolan que tuvo lugar el 18 de mayo en la Cámara de los Comunes, la oposición laborista descalificó el Informe y sugirió al Gobierno que efectuara un «estudio serio" (Le Monde 22.5.95).

Parece que el Informe en cualquier caso no es la última palabra en lo que respecta al establecimiento de normas para la moralización de la vida pública. Se echan en falta, investigaciones sobre la financiación de los partidos políticos -algo a lo que parece negarse el Primer Ministro y en el tema de los MP, el debate continúa abierto. En espera de más respuestas no es extraño que John Major haya propuesto crear una nueva Comisión para estudiar las propuestas del Informe Nolan.
- Funcionario del Cuerpo Superior de Administradores Civiles del Estado.

1 Recientemente, dos cargos electos (conservadores) han sido acusados de recibir unas 1.000 libras esterlinas (aproximadamente 200.000 pesetas) de parte de un grupo de empresas por realizar preguntas en los Comunes y otro diputado, Sir Jimmy Wigging, para disimular sus relaciones con un grupo de presión, presentó una enmienda en nombre de uno de sus companeros, el antiguo campeón de atletismo, Sebastián Coe, sin haberle informado previamente (Le Monde, 22-5-95).

2 .Honor en el servicio público. El Informe de Lord Nolan es un reproche a una época deshonesta. The Guardian 12-5-95.

3 Un punto conflictivo, a nuestro juicio, de este esquema consiste precisamente en este derecho de recurso de las decisiones de la Comisión al Primer Ministro. Ciertamente puede ser embarazoso para un Ministro que acaba de ser cesado tener que exponer sus planes profesionales futuros ante el Primer Ministro que le cesó, máxime si los ceses coinciden con un cambio de Gobierno de distinto signo. Los autores del informe son conscientes de esta dificultad: •Hemos considerado si un cambio de Gubierno haria inviable el procedimiento; sin embargo, confiamos en las tradicionales relaciones de buen entendimiento entre adversarios politicos, por lo que no vemos razón para dudar de que el Primer Ministro de un partido pueda bacerse cargo convenientemente de los recursos planteados por los Ministros de otros Gobiernos, juicio que parece insólito para ser trasplantado a otras latitudes.

4 En Estados Unidos los empleados del Gobierno Federal pueden recibir regalos por valor de mercado no superior a $20 \$$ en cada ocasión, sin que puedan superar los $50 \$$ al año procedentes de una única fuente externa, según la nueva regulación de *Normas de Conducta Ética para empleados de la Rama Ejecutiva-, aprobada por la Administración Clinton y que entró en vigor en enero de 1993. 